\title{
Modeling the Geometrical Relations of the Elements of the Production System in the Dynamic Realization of their Manipulation Activity
}

\author{
Vladimír Rudy ${ }^{1, *}$, Gabriela lžaríková ${ }^{2}$ \\ ${ }^{1}$ Technical University of Košice, Faculty of Mechanical Engineering, Institute of Industrial Engineering and Management, Košice, Slovakia \\ ${ }^{2}$ Technical University of Košice, Faculty of Mechanical Engineering, Department of Applied Mathematics and Informatics, Košice, Slovakia
}

\begin{abstract}
Optimization of manipulation activity and testing of collision relations of construction components in the production systems is an important project activity. Particularly in the design of automated manufacturing systems increased attention should be paid to modeling the functional and spatial relationships of components that perform manipulation activities in the production area. The paper characterizes the approach applied to modeling the geometrical relations of the elements in the production system of the dynamic realization of their manipulation activity.
\end{abstract}

Keywords: production system, designing handling processes, analytical modeling, graphic modeling, coordinate system, working space of production systems, manipulation, collision testing of physical elements of production systems.

\section{Model for Collision Testing of Manufacturing System Components for Handling Operations}

When projecting production workplaces is needed to optimize the technology sessions, handling, management and other functional areas. Handling operations optimization of the producted object handling is preferably addressed by zonal study. This is based on track movements in handling and it depends on the orientation of the device mounting area and the orientation of the output of the fixture device relative to the robot, and the robot kinematics.

Satisfactory orientation are selected according to two criteria:

1. compatibility orientation and type of the manipulated object oriented movement when removing an object from the mounting device,

2. exclusion of the collision object with a mounting device, it is necessary to determine the path of movement when handling near the mounting device.

When testing the collisions of the components of an automated manufacturing system in its working zone, it is necessary to determine the path of their movements. A partial algorithm for testing the movement path of a robot with a manufacturing object when it is mounted in a clamping device is on the Fig.1. The analysis is based on the following steps: 
Manipulation of an object is tested in the workspace of the production facility in the elementary steps to determine whether there is a collision.

This cyclical process is repeated if a collision is detected when inserting an object or output from the device new variants must be analyzed of the manipulation cycle.

- The process is repeated on other automated manufacturing system equipment.

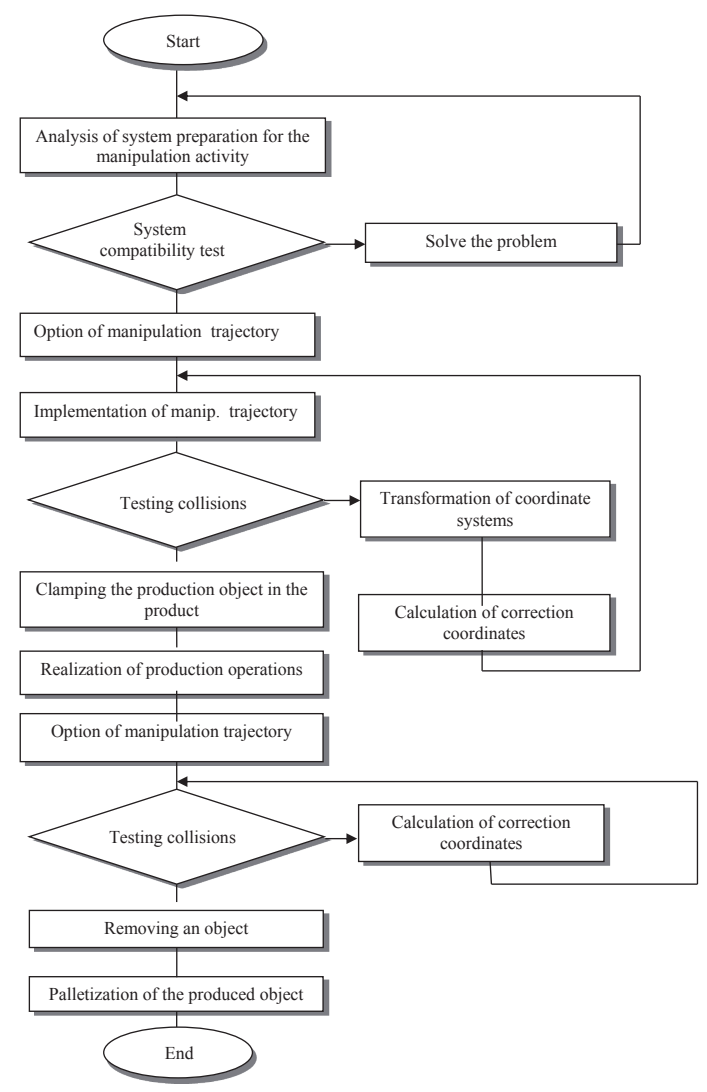

Fig. 1: A partial algorithm for testing the movement path of a robot.

Testing collision manipulated object with a mounting device, may be performed either graphical or analytical.

For analytical testing we introduce the coordinate system of the robot gripper $x_{C}, y_{C}, z_{C}$, starting $O_{C}$ in the middle of the jaw object (Tab. 1). Axis $z_{C}$ is the vertical axis direction and $y_{C}$ a direction of travel when moving between devices. All parts of the arm (tentacle and object in it) is approximated to the blocks with edges parallel to the axis $x_{C}, y_{C}, z_{C}$. The dimensions and location of any such cuboid $m$-th $(\mathrm{m}=1,2 \ldots \mathrm{M})$ are given by the coordinates of its edges $x_{m}^{\prime}, y_{m}^{\prime}, z_{m}^{\prime}, x_{m}^{\prime \prime}, y_{m}^{\prime \prime}, z_{m}^{\prime \prime}$ in view of the gripper coordinate system. Given the approximate shape of the device and the object do not overlap feature is the smallest of any vertical coordinates $x^{\prime \prime}, y^{\prime \prime}, z^{\prime \prime}$ one element of the corresponding largest coordinate $x^{\prime}, y^{\prime}, z^{\prime}$ the second element.

To express the elements of the robot and devices need to have their expression in a single coordinate system. In this case, it is advisable to use a coordinate system of the robot $x_{P}, y_{P}, z_{P}$ (Tab. 2)

Tab. 1: Individual coordinate systems of the production object, the tentacle and the clamping device of the machine.

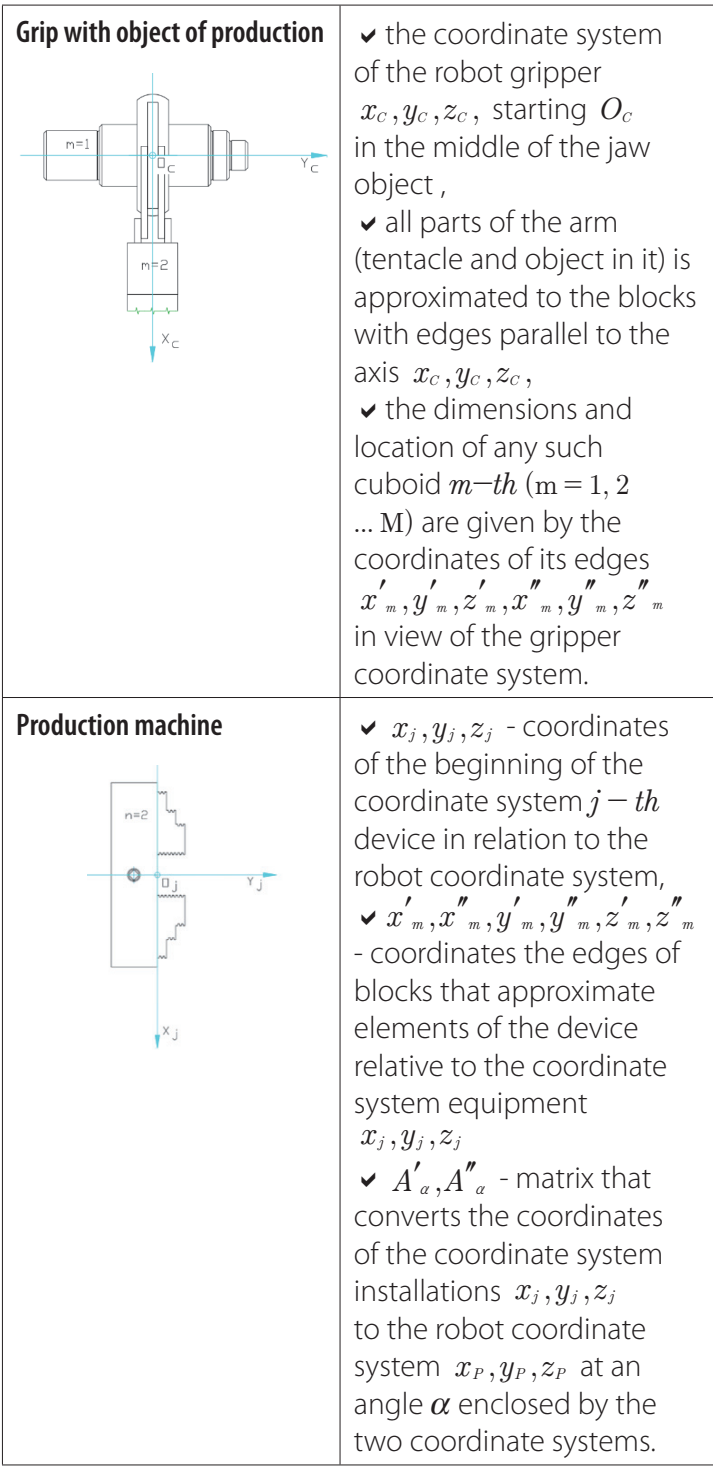


Tab. 2: Integrated coordinate system for testing a handling activity.

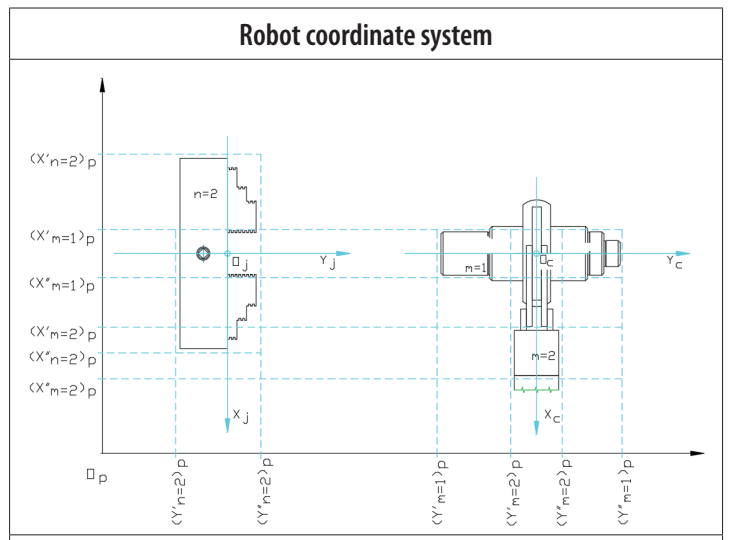

$\checkmark$ coordinate system of the robot $x_{P}, y_{P}, z_{P}$

$\checkmark$ in the coordinate system converted coordinate

edge blocks that approximate device elements as follows:

$r_{n}^{\prime}=r_{j}+A_{\alpha} \cdot r_{n} \quad r_{n}^{\prime \prime}=r_{j}+A_{\alpha}^{\prime \prime} \cdot r_{n}$, where

$r_{n}^{\prime}=\left|\begin{array}{c}\left(x_{n}^{\prime}\right)_{P} \\ \left(y_{n}^{\prime}\right)_{P} \\ \left(z_{n}^{\prime}\right)_{P}\end{array}\right| \quad r_{n}^{\prime \prime}=\left|\begin{array}{c}\left(x^{\prime \prime}\right)_{P} \\ \left(y^{\prime \prime}\right)_{P} \\ \left(z^{\prime \prime}\right)_{P}\end{array}\right| \quad r_{j}=\left|\begin{array}{c}x_{j} \\ y_{j} \\ z_{j}\end{array}\right| \quad r_{n}=\left|\begin{array}{c}x^{\prime}{ }_{n} \\ x^{\prime \prime}{ }_{n} \\ y_{n}^{\prime} \\ y^{\prime \prime}{ }_{n} \\ z_{n}^{\prime} \\ z^{\prime \prime}{ }_{n}\end{array}\right|$

$\checkmark\left(x_{n}^{\prime}\right)_{P},\left(y_{n}^{\prime}\right)_{P},\left(z_{n}^{\prime}\right)_{P}$ - coordinate played cuboid, most remote in the positive direction of the axis robot $\checkmark\left(x_{n}^{\prime \prime}\right)_{P},\left(y_{n}^{\prime \prime}\right)_{P},\left(z_{n}^{\prime \prime}\right)_{P}$ - analogous to the coordinates corresponding closest edges $\left(x_{P}, y_{P}, z_{P}\right)$

$\checkmark x_{j}, y_{j}, z_{j}$-coordinates of the beginning of the coordinate system $j-t h$ device in relation to the robot coordinate system.

First, in the coordinate system converted coordinate edge blocks that approximate device elements as follows: $r_{n}^{\prime}=r_{j}+A_{\alpha} \cdot r_{n}$ $r_{n}^{\prime \prime}=r_{j}+A_{\alpha}^{\prime \prime} \cdot r_{n}$, where

$$
r_{n}^{\prime}=\left|\begin{array}{c}
\left(x_{n}^{\prime}\right)_{P} \\
\left(y_{n}^{\prime}\right)_{P} \\
\left(z_{n}^{\prime}\right)_{P}
\end{array}\right| \quad r_{n}^{\prime \prime}=\left|\begin{array}{c}
\left(x_{n}^{\prime \prime}\right)_{P} \\
\left(y_{n}^{\prime \prime}\right)_{P} \\
\left(z^{\prime \prime}\right)_{P}
\end{array}\right| \quad r_{j}=\left|\begin{array}{c}
x_{j} \\
y_{j} \\
z_{j}
\end{array}\right| \quad r_{n}=\left|\begin{array}{c}
x^{\prime}{ }_{n} \\
x^{\prime \prime}{ }_{n} \\
y^{\prime} \\
y^{\prime \prime}{ }_{n} \\
z_{n}^{\prime} \\
z^{\prime \prime}{ }_{n}
\end{array}\right|
$$

- $\left(x_{n}^{\prime}\right)_{P},\left(y_{n}^{\prime}\right)_{P},\left(z_{n}^{\prime}\right)_{P}$ - coordinate of edges cuboid, most remote in the positive direction of the axis robot $\left(x_{P}, y_{P}, z_{P}\right)$,

- $\left(x^{\prime \prime}\right)_{P},\left(y_{n}^{\prime \prime}\right)_{P},\left(z^{\prime \prime}\right)_{P}$ - analogous to the coordinates corresponding closest edges,

- $x_{j}, y_{j}, z_{j}$ - coordinates of the beginning of the coordinate system $j-t h$ device in relation to the robot coordinate system, $x_{n}^{\prime}, x_{n}^{\prime \prime}, y_{n}^{\prime}, y_{n}^{\prime \prime}, z_{n}^{\prime}, z_{n}^{\prime \prime}$ coordinates the edges of blocks that approximate elements of the device relative to the coordinate system equipment $x_{j}, y_{j}, z_{j}$,

$A^{\prime}{ }_{\alpha}, A^{\prime \prime}{ }_{\alpha}$ - matrix that converts the coordinates of the coordinate system installations $x_{j}, y_{j}, z_{j}$ to the robot coordinate system $x_{P}, y_{P}, z_{P}$ at an angle $\alpha$ enclosed by the two coordinate systems.

After converting the coordinates of the approximated edges of the elements in the coordinate system of the robot is determined by moving the position of the coordinate system of the gripper relative to the coordinate system of the robot according to the formula:

$r_{C X}=r_{j}+B_{\alpha}\left(r_{i j}+C_{\alpha} r_{P i}\right)+r_{T}$, where

$$
r_{C X}=\left|\begin{array}{l}
x_{C} \\
y_{C} \\
z_{C}
\end{array}\right| r_{i j}=\left|\begin{array}{l}
x_{i j} \\
y_{i j} \\
z_{i j}
\end{array}\right| \quad r_{P i}=\left|\begin{array}{c}
x_{P i} \\
y_{P i} \\
z_{P i}
\end{array}\right| \quad r_{T}=\left|\begin{array}{c}
x_{T} \\
y_{T} \\
z_{T}
\end{array}\right|
$$

$x_{C}, y_{C}, z_{C}$-coordinates of the point $O_{C}$ relative to the system $x_{P}, y_{P}, z_{P}$,

- $x_{i j}, y_{i j}, z_{i j}$ - coordinates of the object $O_{i}$ placed on the device or shortly after release,

$x_{P i}, y_{P i}, z_{P_{i}}$-coordinates of the gripper relative to the coordinate system of the object $x_{i}, y_{i}, z_{i}$,

- $x_{T}, y_{T}, z_{T}$, - variable position of the gripper for handling the direction of respective axes of coordinates of the robot

- $B_{\alpha}$ - matrix which calculates the coordinates in the rotation device relative to the robot

$B=\left|\begin{array}{ccc}\cos \alpha & -\sin \alpha & 0 \\ \sin \alpha & \cos \alpha & 0 \\ 0 & 0 & 1\end{array}\right|$

- $C_{\alpha}$ matrix that takes into account the different types of orientation of the object relative to the apparatus.

Furthermore, for each thus recalculated position coordinates of the robot gripper determined as:

$$
\left(r_{m}\right)_{P}=r_{C X}+r_{m}^{\prime}\left(r_{m}^{\prime \prime}\right)_{P}=r_{C X}+r_{m}^{\prime \prime}
$$$$
\left(r_{m}^{\prime}\right)_{P}=\left|\begin{array}{c}
\left(x_{m}^{\prime}\right)_{P} \\
\left(y_{m}^{\prime}\right)_{P} \\
\left(z_{m}^{\prime}\right)_{P}
\end{array}\right| \quad\left(r_{m}^{\prime \prime}\right)_{P}=\left|\begin{array}{c}
\left(x^{\prime \prime}\right)_{P} \\
\left(y_{m}^{\prime \prime}\right)_{P} \\
\left(z_{m}^{\prime \prime}\right)_{P}
\end{array}\right|
$$

$r_{m}^{\prime}=\left|\begin{array}{c}x_{m}^{\prime} \\ y_{m}^{\prime} \\ z_{m}^{\prime}\end{array}\right| \quad r_{m}^{\prime \prime}=\left|\begin{array}{c}x^{\prime \prime}{ }_{m} \\ y^{\prime \prime}{ }_{m} \\ z^{\prime \prime}{ }_{m}\end{array}\right|$ where 
- $\left(x_{m}^{\prime}\right)_{P},\left(y_{m}^{\prime}\right)_{P},\left(z_{m}^{\prime}\right)_{P}$ - coordinates of the edges of the $\mathrm{m}$-th block a maximum distance in the positive direction of the coordinate axes of the robot,

- $\left(x_{m}^{\prime \prime}\right)_{P},\left(y_{m}^{\prime \prime}\right)_{P},\left(z_{m}^{\prime \prime}\right)_{P}$ - analogous coordinates, corresponding closest edges.

These coordinates elements of the robot and the devices are expressed in a single coordinate system, which allows the comparison and elimination of collisions of the robot with the device.

\section{Analytical Determination of the Position of the Manipulated Object when Performing Manipulation Activity in the Production System}

Location description of mounted object is closely related to the issue of zonal projections. It has a particular impact on the size of the robot handling area. If the robot movements in operating the equipment, there is a need to determine the position of the robot with respect to a well-defined starting point. This place, assign a coordinate (stationary) system $(O, x, y, z)$. The system $\left(O_{1}, x_{1}, y_{1}, z_{1}\right)$ is the coordinate system of the robot (moving), system $\left(O_{2}, x_{2}, y_{2}, z_{2}\right)$ is the coordinate system of process equipment and the coordinate system $\left(O_{s}, x_{s}, y_{s}, z_{s}\right)$ being a coordinate system the object itself (Fig. 2).

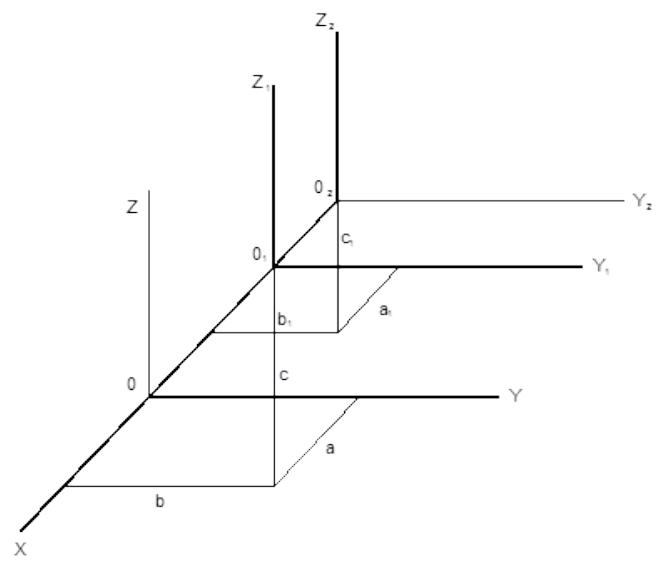

Fig. 2: Coordinate system for direct movement.
If we have a matrix that describes the position of the machine relative to the robot $\left(M_{r z}\right)$, matrix that determines the position of the object relative to the machine $\left(M_{z s}\right)$ and the matrix that determines the position of the robot relative to the stationary coordinate system $\left(M_{p v}\right)$, can be expressed in the matrix $\left(M_{r v s}\right)$ which determines the position of the object relative to the robot.

$$
M_{r v s}=M_{r z} \cdot M_{z s} \text { where }=M_{p v} \cdot\left(\begin{array}{cccc}
1 & 0 & 0 & 0 \\
0 & 1 & 0 & 0 \\
0 & 0 & 1 & 0 \\
a_{1} & b_{1} & c_{1} & 1
\end{array}\right)
$$

The matrix $M_{p v}$ has generally the form:

$$
M_{p v}=\left(\begin{array}{llll}
x_{1} & y_{1} & z_{1} & 1
\end{array}\right)=\left(\begin{array}{llll}
x & y & z & 1
\end{array}\right)\left(\begin{array}{llll}
1 & 0 & 0 & 0 \\
0 & 1 & 0 & 0 \\
0 & 0 & 1 & 0 \\
a & b & c & 1
\end{array}\right)
$$

Position of the robot with respect to the technological equipment expressed matrix $M_{r z}$ has the form:

$$
M_{r z}=\left(\begin{array}{llll}
x_{2} & y_{2} & z_{2} & 1
\end{array}\right)=\left(\begin{array}{llll}
x_{1} & y_{1} & z_{1} & 1
\end{array}\right)\left(\begin{array}{cccc}
1 & 0 & 0 & 0 \\
0 & 1 & 0 & 0 \\
0 & 0 & 1 & 0 \\
a_{1} & b_{1} & c_{1} & 1
\end{array}\right)
$$

Property of technological equipment, in general, the matrix expressed by $M_{z s}$ :

$$
M_{z s}=\left(\begin{array}{cccc}
1 & 0 & 0 & a_{s} \\
0 & \cos \alpha_{s} & -\sin \alpha_{s} & 0 \\
0 & \sin \alpha_{s} & \cos \alpha_{s} & 0 \\
0 & 0 & 0 & 1
\end{array}\right)
$$

The final position of the object relative to the coordinate system $(O, x, y, z)$ is given by the product of the matrices:

$$
M_{r v s}=\left(\begin{array}{llll}
x & y & z & 1
\end{array}\right)\left(\begin{array}{cccc}
1 & 0 & 0 & 0 \\
0 & 1 & 0 & 0 \\
0 & 0 & 1 & 0 \\
a & b & c & 1
\end{array}\right)\left(\begin{array}{cccc}
1 & 0 & 0 & 0 \\
0 & 1 & 0 & 0 \\
0 & 0 & 1 & 0 \\
a_{1} & b_{1} & c_{1} & 1
\end{array}\right)\left(\begin{array}{cccc}
1 & 0 & 0 & a_{s} \\
0 & \cos \alpha_{s} & -\sin \alpha_{s} & 0 \\
0 & \sin \alpha_{s} & \cos \alpha_{s} & 0 \\
0 & 0 & 0 & 1
\end{array}\right)=\left(\begin{array}{llll}
A & B & C & D
\end{array}\right)
$$


$A=x+a+a_{1}$

$B=\cos \alpha_{s}\left(y+b+b_{1}\right)+\sin \alpha_{s}\left(z+c+c_{1}\right)$

$C=-\sin \alpha_{s}\left(y+b+b_{1}\right)+\cos \alpha_{s}\left(z+c+c_{1}\right)$

$D=a_{s}\left(x+a+a_{1}\right)+1$

where $x, y, z, x_{1}, y_{1}, z_{1}$ - are three-dimensional space vectors.

According to mathematical procedure for determining the position of an object is valid if the relative positions of components of the translational (straight). If the object moves in a circular path about a given radius of a matrix expressing the position of the robot to a coordinate system $(O, x, y, z)$ will have the form:

$$
M_{p v}=\left(\begin{array}{cccc}
\alpha_{11} & \alpha_{12} & \alpha^{13} & a_{i} \\
\alpha_{21} & \alpha_{22} & \alpha_{23} & b_{i} \\
\alpha_{31} & \alpha_{32} & \alpha^{33} & c_{i} \\
0 & 0 & 0 & 1
\end{array}\right)
$$

Matrix $M_{r z}$ and $M_{z s}$ have the same form. The result is a statement of the final position of the object, which we obtain the product of the matrix $M_{r z}$ and $M_{z s}$.

$M_{r v s}=M_{r z} \cdot M_{z s}$ where $M_{r z}=M_{p v} \cdot\left(\begin{array}{cccc}1 & 0 & 0 & 0 \\ 0 & 1 & 0 & 0 \\ 0 & 0 & 1 & 0 \\ a_{1} & b_{1} & c_{1} & 1\end{array}\right)$

$$
\begin{aligned}
& M_{r v s}=\left(\begin{array}{cccc}
\alpha_{11} & \alpha_{12} & \alpha^{13} & a_{i} \\
\alpha_{21} & \alpha_{22} & \alpha_{23} & b_{i} \\
\alpha_{31} & \alpha_{32} & \alpha^{33} & c_{i} \\
0 & 0 & 0 & 1
\end{array}\right)\left(\begin{array}{cccc}
1 & 0 & 0 & 0 \\
0 & 1 & 0 & 0 \\
0 & 0 & 1 & 0 \\
a_{1} & b_{1} & c_{1} & 1
\end{array}\right)\left(\begin{array}{cccc}
1 & 0 & 0 & a_{s} \\
0 & \cos \alpha_{s} & -\sin \alpha_{s} & 0 \\
0 & \sin \alpha_{s} & \cos \alpha_{s} & 0 \\
0 & 0 & 0 & 1
\end{array}\right)=\left(\begin{array}{cccc}
M_{11} & M_{12} & M_{13} & M_{14} \\
M_{21} & M_{22} & M_{23} & M_{24} \\
M_{31} & M_{32} & M_{33} & M_{34} \\
M_{41} & M_{42} & M_{43} & M^{44}
\end{array}\right) \\
& M_{11}=\alpha_{11}+a_{i} \cdot a_{1} \\
& M_{21}=\alpha_{21}+b_{i} \cdot a_{1} \\
& M_{12}=\left(\alpha_{12}+a_{i} . b_{1}\right) \cos \alpha_{s}+\left(\alpha_{13}+a_{i} . c_{1}\right) \sin \alpha_{s} \\
& M_{22}=\left(\alpha_{22}+b_{i} . b_{1}\right) \cos \alpha_{s}+\left(\alpha_{23}+b_{i} . c_{1}\right) \sin \alpha_{s} \\
& M_{13}=-\left(\alpha_{12}+a_{i} . b_{1}\right) \sin \alpha_{s}+\left(\alpha_{13}+a_{i} . c_{1}\right) \cos \alpha_{s} \\
& M_{23}=-\left(\alpha_{22}+b_{i} \cdot b_{1}\right) \sin \alpha_{s}+\left(\alpha_{23}+b_{i} \cdot c_{1}\right) \cos \alpha_{s} \\
& M_{14}=\left(\alpha_{11}+a_{i} . a_{1}\right) a_{s}+a_{i} \\
& M_{24}=\left(\alpha_{21}+b_{i} . a_{1}\right) a_{s}+b_{i} \\
& M_{31}=\alpha_{31}+c_{i} \cdot a_{1} \\
& M_{41}=a_{1} \\
& M_{32}=\left(\alpha_{32}+c_{i} \cdot b_{1}\right) \cos \alpha_{s}+\left(\alpha_{33}+c_{i} . c_{1}\right) \sin \alpha_{s} \\
& M_{42}=b_{1} \cos \alpha_{s}+c_{1} \sin \alpha_{s} \\
& M_{33}=-\left(\alpha_{32}+c_{i} \cdot b_{1}\right) \sin \alpha_{s}+\left(\alpha_{33}+c_{i} \cdot c_{1}\right) \cos \alpha_{s} \\
& M_{43}=-b_{1} \sin \alpha_{s}+c_{1} \cos \alpha_{s} \\
& M_{34}=\left(\alpha_{31}+c_{i} . a_{1}\right) a_{s}+c_{i} \\
& M_{44}=a_{1} \cdot a_{s}+1
\end{aligned}
$$

Mathematical computations of spatial-zonal optimization are relatively labor-intensive, is their algorithmization and computerized solutions are necessary.

\section{Conclusions}

The importance of integration in the construction components of production systems is their interconnections and optimal activity in the innovative projects is increasing. Modeling and simulation verification through mathematical models contained in advanced commercial but primarily purpose-developed software products is implemented in a number of future production projects that are addressed at the workplaces of the authors.

\section{Acknowledgments}

This article was created by implementation of the project VEGA 1/0853/16 New project technologies for the creation and implementation of future factories.

\section{References and Notes}

[1] Buda, J., Kováč, M.: Projektovanie a prevádzka robotizovaných systémov. Alfa Bratislava, 1990, ISBN 80-05-006802

[2] Djačenko, V., A., Timofeev, A.,H.: Nekotorije voprosy projektirovanija robotizirovannych tehnologičeskich kompleksov. Leningradskij institut, Leningrad, 1981

[3] Ižaríková, G.: Modely pre automatizované projektovanie montážnych systémov. Diz. práca, SjF TU v Košiciach, 2008

[4] Ižaríková, G., Rudy, V., Korba, P.: The Model of topological 
relations constructed equipments of structure productice systems. In: Internationale Journal of interdisciplinary in theory and practice. Vol. 1, no. 1 (2013), p. 32-35. - ISSN 2344-2409

[5] Ižaríková, G., Palaščaková, D.: Modeling trajectory on the robotic systems of interpolation methods. In: Annals of Faculty Engineering Hunedoara. Vol. 13, no. 4 (2015), p. 263266. - ISSN 1584-2665

[6] Kováč, M., Buda, J., Šimšik, D.: Projektovanie výrobných systémov, Alfa Bratislava, 1991, ISBN 80-05-00709-4

[7] Kováč, J.: Projektovanie výrobných procesov a systémov. Edícia EQUAL, TU SjF v Košiciach, 2006, ISBN 80 -8073-7207

[8] Kováč, M., Kováč, J.: Inovačné projektovanie výrobných procesov a systémov. Edícia vedeckej a odbornej literatúry. SjF TU v Košiciach. 2011. ISBN 978-80-553-0805-0

[9] Kováč, J., Liška, O., Pečovská, K.: Modeling of the cell structures of robotized systems: Modelovanie bunkových štruktúr robotizovaných systémov. In: Sborník vědeckých prací Vysoké školy báňské, Technické univerzity Ostrava, VŠB, 2005, p. 65-70, ISBN 802480882X

[10] Madarász, L, Kováč, J., Lí̌̌ka, O.: Program System for Parametric Modelling of Production Utilities and Production Systems. INNES 2000, Slovinsko, 2000, pp 145-147

[11] Pečovská, K.: Modeling of production system, Doctoral thesis, SjF TU Košice, 1998, (on Slovák only)

\section{Biographical notes}

doc. Ing. Vladimír Rudy, PhD.: is associate professor at the Institute of Management, Industrial and Digital Engineering, of the Faculty of Mechanical Engineering, Technical University in Košice. In 1998 she graduated at the University of Economics in Bratislava. PhD. degree received in Engineering Technologies and Materials from the Technical University of Košice in 2006. She is associate professor in Industrial Engineering from 2010 year. Her research interests include strategic, financial, and crisis management, controlling and innovations.

Mgr. Gabriela Ižaríková, PhD.: graduated on the P.J. Safarik University in Košice, Faculty of Science in 1997. She received PhD. in 2009 at the Faculty of Mechanical Engineering, Technical University of Košice. She has worked at Department of Applied Mathematics at the Faculty of Mechanical Engineering, Technical University of Košice since 1997. Her research interests are focused on addressing the relationships inside the zone topology problems and on applications of mathematical and statistical methods in different areas of science. At present, she works as a lecturer at the Department of Applied Mathematics and Informatics of the Faculty of Mechanical Engineering, Technical University of Košice. 